\title{
Freestream velocity-profile measurement in a large-scale, high-enthalpy reflected-shock tunnel
}

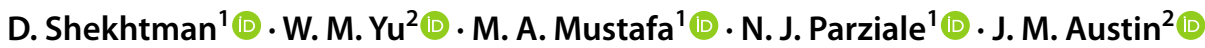

Received: 30 December 2020 / Revised: 8 April 2021 / Accepted: 10 April 2021

(c) The Author(s), under exclusive licence to Springer-Verlag GmbH Germany, part of Springer Nature 2021

\begin{abstract}
We apply Krypton Tagging Velocimetry (KTV) to measure velocity profiles in the freestream of a large, national-scale highenthalpy facility, the T5 Reflected-Shock Tunnel at Caltech. The KTV scheme utilizes two-photon excitation at $216.67 \mathrm{~nm}$ with a pulsed dye laser, followed by re-excitation at $769.45 \mathrm{~nm}$ with a continuous laser diode. Results from a nine-shot experimental campaign are presented where $\mathrm{N}_{2}$ and air gas mixtures are doped with krypton, denoted as $99 \% \mathrm{~N}_{2} / 1 \% \mathrm{Kr}$, and $75 \%$ $\mathrm{N}_{2} / 20 \% \mathrm{O}_{2} / 5 \% \mathrm{Kr}$, respectively. Flow conditions were varied through much of the T5 parameter space (reservoir enthalpy $h_{R} \approx 5-16 \mathrm{MJ} / \mathrm{kg}$ ). We compare our experimental freestream velocity-profile measurements to reacting, Navier-Stokes nozzle calculations with success, to within the uncertainty of the experiment. Then, we discuss some of the limitations of the present measurement technique, including quenching effects and flow luminosity; and, we present an uncertainty estimate in the freestream velocity computations that arise from the experimentally derived inputs to the code.
\end{abstract}

\section{Graphic Abstract}

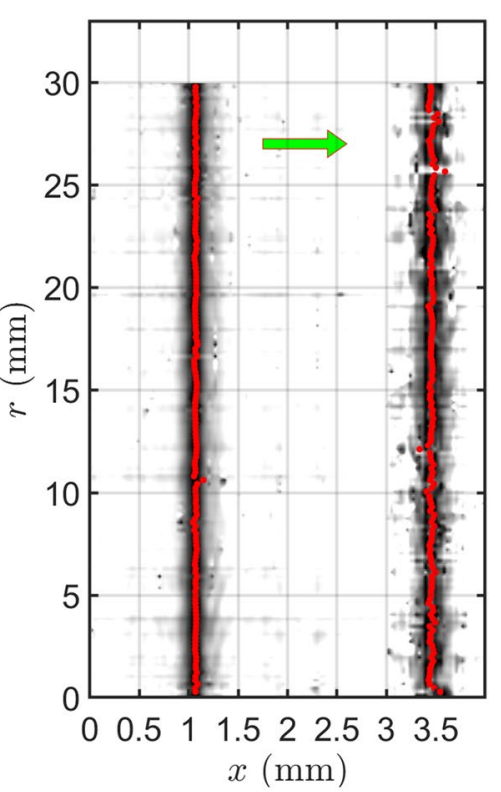

D. Shekhtman

dshekhtm@stevens.edu

Extended author information available on the last page of the article

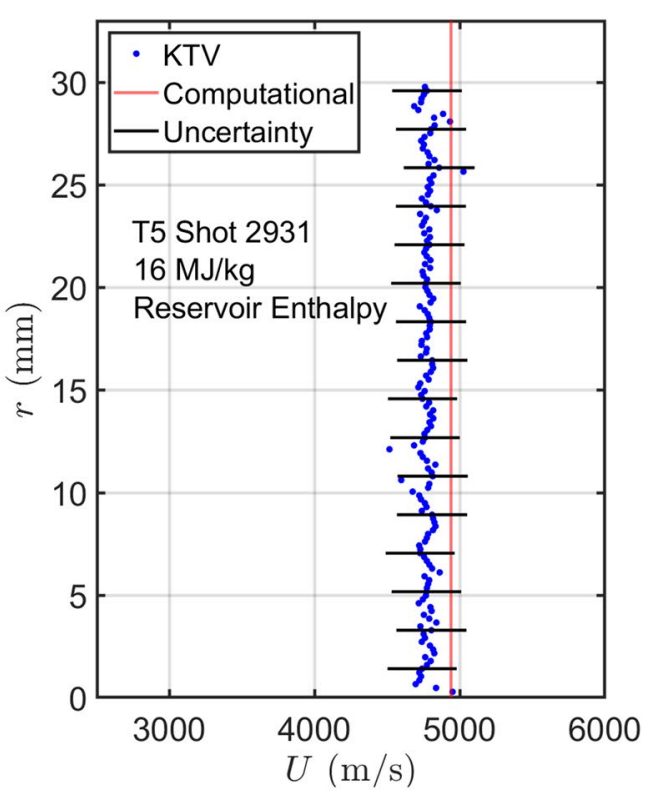

1 Introduction

High-speed flow is characterized by complex phenomena such as shock waves, compressible turbulence, and nonequilibrium thermochemistry. There is a pressing need for optical flowfield measurement techniques that can provide 
more insight into these phenomena and their interactions than can be achieved by interpretation of surface measurements (e.g., heat flux and pressure) and conventional optical diagnostics (e.g., schlieren). Ground tests are a critical step before flight, as well as an opportunity to examine fundamental flow interactions in detail; however, no single ground-test facility can recreate all high-speed flow conditions for free flight (Hornung 1993; Lu and Marren 2002; Schneider 2008). An impulse facility, such as a reflectedshock tunnel or expansion tube/tunnel, can recreate freeflight enthalpy in ground tests.

Measurements in impulse facilities are notoriously difficult to make due to challenges such as timing, frequency response, influence of the probe on the flow, chemiluminescence, harsh aerothermodynamic measurement environment, high vibrational environment, and, in the case of particle-based techniques, particle injection, and response time. Nonintrusive optical diagnostics can address some of these challenges (Danehy et al. 2018). In this work, we focus on velocity measurements.

Two ubiquitous velocimetry techniques are Laser Doppler Velocimetry (LDV) and Particle Image Velocimetry (PIV) (Tropea et al. 2007). These particle-based measurements rely on the assumption that the tracer particles travel identically with the flow. However, the particle response time can be inadequate in low-density flows with short timescales. At low densities, the Knudsen number of a particle can become large (Loth 2008). This represents a fundamental limitation of particle-based techniques because the slip condition at the particle surface culminates in reduced response time, making critical quantities difficult to measure (Lowe et al. 2014; Williams et al. 2015; Brooks et al. 2018).

Tagging velocimetry (TV) is an attractive alternative to particle-based techniques because TV is not limited by timing issues associated with tracer injection or reduced particle response at Knudsen and Reynolds numbers characteristic of high-speed wind tunnels. Methods of tagging velocimetry include KTV (Parziale et al. 2015; Zahradka et al. 2016; Mustafa et al. 2017b, a, c, 2018; Mustafa and Parziale 2018; Mustafa et al. 2019a, b; Shekhtman et al. 2020), VENOM (Hsu et al. 2009a, b; Sánchez-González et al. 2011, 2012, 2014), APART (Dam et al. 2001; Sijtsema et al. 2002; Van der Laan et al. 2003), RELIEF (Miles et al. 1987, 1989, 1993; Miles and Lempert 1997; Miles et al. 2000), FLEET (Michael et al. 2011; Edwards et al. 2015), STARFLEET (Jiang et al. 2016), PLEET (Jiang et al. 2017), argon (Mills 2016), iodine (McDaniel et al. 1983; Balla 2013), sodium (Barker et al. 1997), acetone (Lempert et al. 2002, 2003; Handa et al. 2014), NH Zhang et al. (2017) and the hydroxyl group techniques (Boedeker 1989; Wehrmeyer et al. 1999; Pitz et al. 2005; André et al. 2017), among others (Hiller et al. 1984; Gendrich and Koochesfahani 1996; Gendrich et al. 1997; Stier and Koochesfahani 1999; Ribarov et al. 1999; André et al. 2018).

Researchers have applied various velocimetry techniques to impulse facilities. McIntosh (1971) used spark tracer and magnetohydrodynamic methods to measure the velocity of the gas in the freestream of a high-enthalpy shock tunnel; the measurements have large uncertainty and require a complex experimental setup. Wagner et al. (2018) used PIV to measure the impulsively started flow over a cylinder in a shock tube. Haertig et al. (2002) and Havermann et al. (2008) used PIV to measure the flow of a cylinder and a jet in a shock tunnel at modest reservoir enthalpy. Parker et al. (2007) used a line-of-sight integrating method to measure freestream velocity via nitric oxide (NO) in the CUBRC LENS I facility. Danehy et al. (2003) used NO as a tracer to measure shear flows in the T2 and T3 reflected-shock tunnels; those measurements used a mixture of approximately 97-99\% N2 and 1-3\% O2 in the driven section to "produce an amount of NO sufficient to produce good fluorescence but that would minimize the amount of the gases $(\mathrm{O} 2, \mathrm{O}$, and NO) that are efficient quenchers." de S. Matos et al. (2018) made velocity measurements in unseeded hypersonic air flows in a reflected-shock tunnel at an enthalpy of approximately $6 \mathrm{MJ} / \mathrm{kg}$; that work presents a strategy where a reference image was taken before the test, which is not possible in some impulse facilities due to vibration.

There are little or no experimental velocimetry data in the literature at high-enthalpy conditions due to the difficulties of performing experiments in impulse facilities (Stalker 1989; Hornung 1993). As such, there are no experimental data with which computational researchers can use to validate their laudable modeling efforts that can capture the relevant physics of nonequilibrium thermochemistry and the Navier-Stokes equations. A review of these modeling efforts may be found in Candler $(2015,2019)$. This dearth of experimental techniques to make measurements in these highenthalpy flows slows the progress of fundamental hypersonic flow-physics research as well as hypersonic vehicle development (Leyva 2017).

In this work, we apply Krypton Tagging Velocimetry (KTV) to measure velocity profiles in the freestream of the T5 Reflected-Shock Tunnel (Hornung 1992) at the California Institute of Technology. We discuss the results from an experimental campaign where the flow conditions were varied through much of the T5 parameter space (reservoir enthalpy $h_{R} \approx 5-16 \mathrm{MJ} / \mathrm{kg}$ ). We compare our experimental freestream velocity-profile measurements to reacting, Navier-Stokes nozzle calculations with success. Then, we discuss some of the limitations of the present measurement technique, including quenching effects, flow luminosity, and we present an uncertainty estimate in the freestream velocity computations that would arise from the experimentally derived inputs to the code. 


\section{Krypton tagging velocimetry}

In this work, excited $\mathrm{Kr}$ serves as the tracer for tagging velocimetry. The use of a metastable noble gas as a tagging velocimetry tracer was first suggested by Mills et al. (2011) and Balla and Everhart (2012). To date, Krypton Tagging Velocimetry (KTV) has been demonstrated by globally seeding high-speed $\mathrm{N}_{2}$ flows with $1 \% \mathrm{Kr}$ and air flows with $5 \%$ Kr. Applications include: 1) an underexpanded jet, constituting the first-ever KTV demonstration (Parziale et al. 2015); 2) mean and fluctuating turbulent boundary-layer profiles in a Mach 2.7 flow (Zahradka et al. 2016); 3) twenty simultaneous profiles over a $20 \mathrm{~mm}$ field-of-view of streamwise velocity and velocity fluctuations in a Mach 2.8 shock-wave/turbulent boundary-layer interaction (Mustafa et al. 2019a); and 4) the freestream of the large-scale AEDC Hypervelocity Tunnel 9 at Mach 10 and Mach 14 (Mustafa et al. 2017c). In these experiments, the researchers used a pulsed dye laser to perform the write step at $214.77 \mathrm{~nm}$ to form a write line and photosynthesize the metastable $\mathrm{Kr}$ tracer; after a prescribed delay, an additional pulsed dye laser was used to re-excite the metastable $\mathrm{Kr}$ tracer to track displacement. Recently, simplified KTV schemes were developed and demonstrated in an underexpanded-jet configuration (Mustafa and Parziale 2018) and in the flow following the incident shock in a shock tube (Mustafa et al. 2019b). These simplified schemes used 1) a single dye laser for the write step with no read laser, or 2) a dye laser for the write step and a simple, continuouswave $(\mathrm{CW})$ laser diode to help boost signal-to-noise ratio (SNR) during the read step.

In this work, we build upon the simplified schemes by using a dye laser and a simple $\mathrm{CW}$ laser diode. We demonstrate the use of two-photon excitation at $216.67 \mathrm{~nm}$, unlike the 212.56 and $214.77 \mathrm{~nm}$ wavelengths used in previous KTV works. The use of the $216.67 \mathrm{~nm}$ wavelength is born out of the need to maximize the SNR of the fluorescence images. Details on the experimental and theoretical work

Table 1 Relevant NIST Atomic Spectra Database Lines Data (Kramida et al. 2020), labels match Fig. 1. Racah nl[K] notation denote $\mathrm{Kr}$ excited states. Transition I is not listed because it represents the justifying the use of $216.67 \mathrm{~nm}$ can be found in Shekhtman et al. (2021).

Following the transitions in the energy level diagram in Fig. 1 along with the relevant transition data in Table 1 (labeled as A, B, C), the KTV scheme is performed as follows:

1. Write Step A pulsed, tunable laser excites krypton atoms to form metastable $\mathrm{Kr}$ via two-photon excitation and $\mathrm{Kr}^{+}$via $(2+1)$ photoionization. Two-photon excitation of $4 p^{6}\left({ }^{1} \mathrm{~S}_{0}\right) \rightarrow 5 p[5 / 2]_{2}(216.67 \mathrm{~nm}$, transition $\mathrm{A})$ and subsequent one-photon ionization (Miller 1989) to $\mathrm{Kr}^{+}$ (216.67 nm, transition B) occur. This is followed by transitions to metastable $5 p[5 / 2]_{2} \rightarrow 5 s[3 / 2]_{2}^{\circ}$ (transition D) and resonance states $5 p[5 / 2]_{2} \rightarrow 5 s[3 / 2]_{1}^{\circ}$ (transition

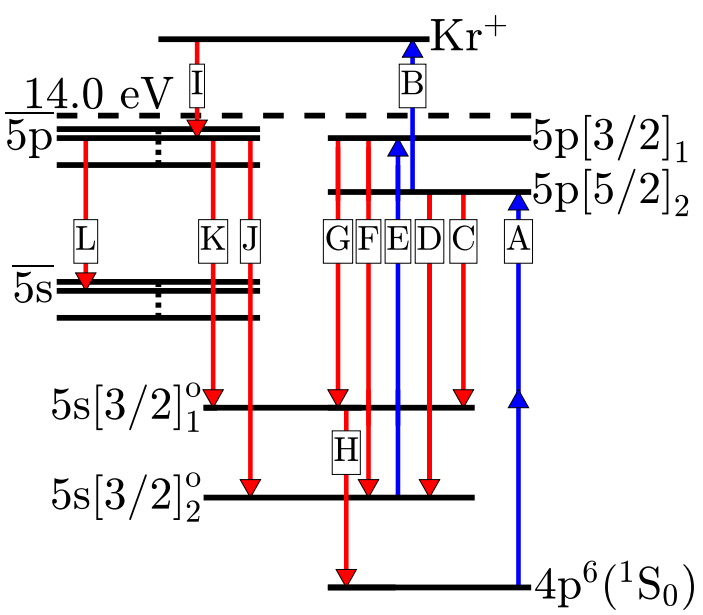

Fig. 1 Energy diagram with Racah $n l[K]_{\text {, }}$ notation. Blue lines indicate stimulated (laser-induced) transitions, and red lines indicate spontaneous transitions. States $\overline{5 p}$ and $\overline{5 s}$ represent the numerous $5 \mathrm{p}$ and $5 \mathrm{~s}$ states that are produced by the recombination process. Transitions $\mathrm{J}, \mathrm{K}$ and $\mathrm{L}$ represent the numerous transitions in the $5 \mathrm{p}-5 \mathrm{~s}$ band. $14.0 \mathrm{eV}$ denotes the ionization limit of $\mathrm{Kr}$. Transition details are in Table 1

recombination process. Entries in the $\mathrm{J} / \mathrm{K} / \mathrm{L}$ row represent order of magnitude estimates for transitions that involve excited $\mathrm{Kr}$ species in the $5 p-5$ s band, as shown in Fig. 1

\begin{tabular}{llllllll}
\hline Transition & $\lambda_{\text {air }}(\mathrm{nm})$ & Nature & $A_{k i}(1 / \mathrm{s})$ & $E_{i}\left(\mathrm{~cm}^{-1}\right)$ & $E_{k}\left(\mathrm{~cm}^{-1}\right)$ & Lower level & Upper level \\
\hline A & 216.670 & Two-photon & - & 0 & 92307.3786 & $4 \mathrm{~s}^{2} 4 \mathrm{p}^{6},{ }^{1} \mathrm{~S}_{0}$ & $5 \mathrm{p}[5 / 2]_{2}$ \\
B & 216.670 & Single-photon & - & 92307.3786 & 112917.62 & $5 \mathrm{p}[5 / 2]_{2}$ & $\mathrm{Kr}$ \\
C & 877.675 & Single-photon & $2.2 \times 10^{7}$ & 80916.7680 & 92307.3786 & $5 \mathrm{~s}[3 / 2]_{1}$ & $5 \mathrm{p}[5 / 2]_{2}$ \\
D & 810.436 & Single-photon & $8.9 \times 10^{6}$ & 79971.7417 & 92307.3786 & $5 \mathrm{~s}[3 / 2]_{2}$ & $5 \mathrm{p}[5 / 2]_{2}$ \\
E/F & 769.454 & Single-photon & $4.3 \times 10^{6}$ & 79971.7417 & 92964.3943 & $5 \mathrm{~s}[3 / 2]_{2}$ & $5 \mathrm{p}[3 / 2]_{1}$ \\
G & 829.811 & Single-photon & $2.9 \times 10^{7}$ & 80916.7680 & 92964.3943 & $5 \mathrm{~s}[3 / 2]_{1}$ & $5 \mathrm{p}[3 / 2]_{1}$ \\
H & 123.584 & Single-photon & $3.0 \times 10^{8}$ & 0 & 80916.7680 & $4 \mathrm{~s}^{2} 4 \mathrm{p}^{6},{ }^{1} \mathrm{~S}_{0}$ & $5 \mathrm{~s}[3 / 2]_{1}$ \\
J/K/L & $750-830$ & Single-photon & $10^{6}-10^{7}$ & 80000.0000 & 90000.0000 & $\overline{5 s}$ & $\overline{5 p}$ \\
\hline
\end{tabular}


$\mathrm{C}$ ), as well as transitions ( $\mathrm{J}, \mathrm{K}$ and $\mathrm{L}$ ) to states resulting from the recombination process (I) (Shiu and Biondi 1977; Dakka et al. 2018). The position of the write line is captured by gated imaging of the laser-induced fluorescence (LIF) from these transitions $(\mathrm{C}, \mathrm{D}, \mathrm{J}, \mathrm{K}, \mathrm{L})$. This is recorded with a camera positioned normal to the flow.

2. Read Step After a prescribed delay, the displacement of the tagged metastable krypton and $\mathrm{Kr}^{+}$is recorded. A CW laser diode excites $5 p[3 / 2]_{1}$ level by $5 s[3 / 2]_{2}^{\mathrm{o}} \rightarrow 5 p[3 / 2]_{1}$ transition $(769.454 \mathrm{~nm}, \mathrm{E})$. This is followed by decay to metastable $5 p[3 / 2]_{1} \rightarrow 5 s[3 / 2]_{1}^{\mathrm{o}}$ $(829.81 \mathrm{~nm}, \mathrm{G})$ and resonance $5 p[3 / 2]_{1} \rightarrow 5 s[3 / 2]_{2}^{\circ}$ $(769.454 \mathrm{~nm}, \mathrm{~F})$ states. The position of the read line is obtained by gated imaging of the LIF from transitions $\mathrm{F}$ and $\mathrm{G}$, and the residual fluorescence from transitions $\mathrm{J}$, $\mathrm{K}$ and $\mathrm{L}$ that result from the recombination process, $\mathrm{I}$.

Due to the need to filter out the freestream luminosity of the T5 reflected-shock tunnel, an 800-850 nm bandpass filter was used, blocking out transitions $\mathrm{C}, \mathrm{E}, \mathrm{F}$, and a portion of the radiation cascade $\mathrm{L}$ that falls below $800 \mathrm{~nm}$. The sacrifice in signal is worthwhile because much of the luminosity is rejected and transitions D and G still fall within our wavelength interval. The filter has the additional benefit of blocking $\mathrm{CW}$ read-laser light scattering (transition $\mathrm{E}$ ).

\section{Experimental setup}

\subsection{T5 reflected-shock tunnel}

All measurements were made in T5, the free-piston-driven reflected-shock tunnel at the California Institute of Technology. It is the fifth in a series of shock tunnels designed to simulate high-enthalpy, real gas effects on the aerodynamics of vehicles flying at hypervelocity speeds through the atmosphere. More information regarding the capabilities of T5 can be found in Hornung (1992). In Fig. 2, the schematic shows the driven section of the shock tube, the nozzle, and the test section along with the equipment required for KTV in T5.

To calculate the freestream run conditions, the conditions of the nozzle reservoir are first determined for each experiment. Using the initial driven section pressure, $P_{1}$, and the measured incident shock speed $U_{s}$, the thermodynamic state is evaluated for the portion of test gas that has been processed by both the incident and reflected shocks. We assume the pressure of this state isentropically expands to the reservoir pressure, $P_{R}$, which accounts for weak expansion or compression waves that are reflected between the contact surface and the shock tube end wall. These calculations were performed using Cantera (Goodwin 2003) with

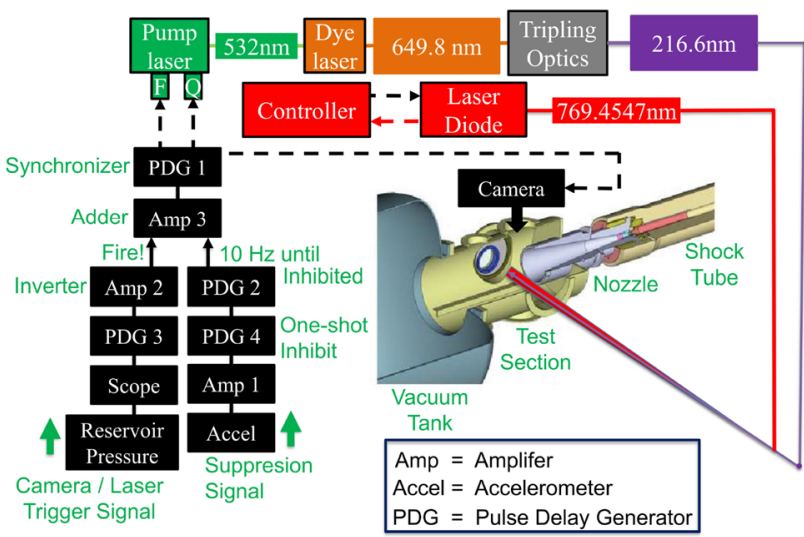

Fig. 2 Experimental setup

the Shock and Detonation Toolbox (Browne et al. 2006). The appropriate thermodynamic data are found in the literature (Gordon and McBride 1999; McBride et al. 2002). Following the evaluation of the reservoir condition, the steady expansion through the contoured nozzle from the reservoir to the freestream is computed by the University of Minnesota Nozzle Code which modeled the flow with the axisymmetric, reacting Navier-Stokes equations assuming turbulent nozzle wall boundary layers (Wright et al. 1996; Candler 2005; Johnson 2000; Wagnild 2012). Finally, the three test-gas mixtures were: (1) $97 \% \mathrm{~N}_{2} / 3 \% \mathrm{Kr}$, (2) $99 \% \mathrm{~N}_{2}$ $/ 1 \% \mathrm{Kr}$, and (3) $75 \% \mathrm{~N}_{2} / 20 \% \mathrm{O}_{2} / 5 \% \mathrm{Kr}$.

\subsection{Laser and camera setup}

The write-laser system for this KTV investigation is a frequency-doubled Quanta Ray Pro-290 Nd:YAG laser and a frequency-tripled Sirah PrecisionScan Dye Laser (DCM dye, DMSO solvent). A schematic of the optical setup is shown in Fig. 2. The Nd:YAG laser pumps the dye laser with $500 \mathrm{~mJ} /$ pulse at a wavelength of $532 \mathrm{~nm}$. The dye laser is tuned to output a $650.01 \mathrm{~nm}$ beam, and frequency tripling (Sirah THU 205) of the dye laser output results in a $216.67 \mathrm{~nm}$ beam, with $4 \mathrm{~mJ}$ of energy entering the test section, a $1350 \mathrm{MHz}$ linewidth, and a $7 \mathrm{~ns}$ pulsewidth at a repetition rate of $10 \mathrm{~Hz}$. The write beam was focused into the test section, near the centerline of the nozzle, just downstream of the exit plane of the nozzle with a $1000 \mathrm{~mm}$ focal-length, fused-silica lens. The beam fluence and spectral intensity at the waist were $1.5 \times 10^{3} \mathrm{~J} / \mathrm{cm}^{2}$ and $1.6 \times 10^{2} \mathrm{~W} /\left(\mathrm{cm}^{2} \mathrm{~Hz}\right)$, respectively. Additionally, we present data with sufficient SNR at least $20-35 \mathrm{~mm}$ away from the focal point where the beam fluence and spectral intensity are lower, $87 \mathrm{~J} / \mathrm{cm}^{2}$ and $9.2 \mathrm{~W} /\left(\mathrm{cm}^{2} \mathrm{~Hz}\right)$, respectively.

The read laser was a Toptica TA Pro 2 watt, CW Laser Diode that generated the $769.4547 \mathrm{~nm}$ laser radiation to excite the metastable $\mathrm{Kr}$ state. As shown in Fig. 2, the 
diode's beam is directed into the test section to overlap with the write beam. The beam output is approximately $15 \mathrm{~mm} \mathrm{x}$ $15 \mathrm{~mm}$ in size at the location of the write beam focus (where the KTV measurement is made), resulting in an intensity of $\approx 900 \mathrm{~mW} / \mathrm{cm}^{2}$. We note this intensity is several orders of magnitude larger than the saturation intensity estimated from Chapter 7 of Eckbreth (1996). A laser diode is much easier to manage than a second pulsed dye laser, as was used previously for KTV involving $214.7 \mathrm{~nm}$ excitation scheme. With little increase in the complexity of the laser setup, the laser diode increases the SNR of the KTV read image. A feedback loop for wavelength reference tracking was implemented to lock the diode on the desired wavelength with Wavelength Meter WS7-4150.

The intensified CCD camera used for all experiments was a Princeton Instruments PIMAX-4 (PM4-1024i-HRFG-18-P46-CM) with two one-inch lens tubes and an AF-S NIKKOR $200 \mathrm{~mm}$ f/2G ED-VR-II prime lens positioned approximately $500 \mathrm{~mm}$ from the write/read location. To maintain a frame rate greater than $20 \mathrm{~Hz}$, a region of interest $1020 \times 512$ was selected from a $1024 \times 1024$ frame, and the image was binned by 6 in the radial/vertical coordinate. The camera gate opened twice: once for $5 \mathrm{~ns}$ immediately following the write-laser pulse and again at a prescribed delay time of $500 \mathrm{~ns}$ for $50 \mathrm{~ns}$ to capture the transitions from the read step. The inherent luminosity of the flow in the T5 tunnel obscured the fluorescence signal. To mitigate this, three $800 \mathrm{~nm}$ high pass and two $850 \mathrm{~nm}$ low pass filters were placed in front of the camera. The filters also decreased the KTV signal; however, this did not outweigh the benefit of reducing the effect of the flow luminosity. A typical image scale of $\approx 32$ pixels $/ \mathrm{mm}$ was recorded before each shot, using Gaussians fitted to the white space between the $1 \mathrm{~mm}$ markings on a Pocket USAF Optical Test Pattern card.

\subsection{Timing scheme for data acquisition}

A timing scheme was implemented to synchronize the time of laser pulsing and camera image acquisition with the firing of the T5 reflected-shock tunnel. The fundamental design requirements of the scheme were to (1) pulse the dye laser at $10 \mathrm{~Hz}$ to maintain its operating temperature, (2) during a tunnel run, suppress the $10 \mathrm{~Hz}$ signal, and (3) pulse the dye laser and trigger the camera once, at the time of measurement. The time of KTV measurement was set to be $0.6-1.8 \mathrm{~ms}$ after the reservoir pressure $P_{R}$ has been established. A representative $P_{R}$ trace is shown in Fig. 3. This choice of delay time is made such that the measurement occurs after the nozzle start-up (1 ms in Fig. 3), but before the drive-gas contamination or arrival of the expansion fan ( $2 \mathrm{~ms}$ in Fig. 3). The choice of delay time is determined by referencing past T5 experiments; see, for example, more details on driver-gas contamination in Sudani and Hornung (1998) and Sudani et al. (2000).

Figure 2 illustrates how the timing scheme controls the dye laser and camera, noting that the $\mathrm{CW}$ laser is left on throughout the experiment. Pulse delay generator (PDG) 2 provides a $10 \mathrm{~Hz}$ pulse to the dye laser and camera. Amplifier (AMP) 3 adds the contributions of PDG 2 and PDG 3. The output of AMP 3 triggers PDG 1, which synchronizes the triggering of the dye laser and camera $1.5 \mathrm{~ms}$ after the rising edge of each trigger pulse. At the start of the tunnel run, an accelerometer senses the tunnel recoil and triggers PDG 4, which sends a single, one-shot inhibit signal to PDG 2 , thus suppressing the $10 \mathrm{~Hz}$ signal for 10 seconds. Once the incident shock is reflected at the end of the shock tube, the reservoir pressure rises sufficiently for the reservoir pressure transducer to trigger in sequence an oscilloscope and PDG3, which sends a TTL pulse to AMP 2. The TTL pulse is inverted by AMP 2 and is subtracted by AMP 3. Signals produced by PDG 2 and PDG 3 are essentially added. Through AMP 3, this TTL pulse both fires the dye laser and triggers the camera $0.6-1.8 \mathrm{~ms}$ after the rising edge of the reservoir transducer.

The length of the pause that the laser system experiences is less than $200 \mathrm{~ms}$. This is the time between the accelerometer inhibiting the laser and the reservoir pressure triggering it to make the measurement. This is essentially the time between the T5 piston starting to move and the establishment of reservoir pressure. $200 \mathrm{~ms}$ is longer than the $10 \mathrm{~Hz}$ operating frequency, but it was observed that there was an acceptable loss of power in the dye laser during the "write pulse."

\section{Results}

In this section, we present results for the experiments in $\mathrm{N}_{2}$ and air. Corresponding flow conditions and gas mixtures are listed in Table 2. To process the KTV exposures, the line centers were found in the following manner:

(1) An image was cropped to an appropriate field of view and normalized. For each row in the image, the minimum was subtracted off, and row elements were normalized by the row maximum. This resulted in some horizontal streakiness in the processed images. To remove background offset, a global mean was subtracted off from the image, followed by normalization by a global maximum.

(2) A two-dimensional Wiener adaptive-noise removal filter was applied. The Wiener-filter stencil was 1 pixel in the streamwise direction and 8 pixels in the spanwise direction. 
Table 2 Experimental conditions grouped approximately by reservoir enthalpy. Shot refers to the experimental shot number. Gas composition is given in percent by mole. $P_{R}, T_{R}$, and $h_{R}$ are the reservoir pressure, temperature, and mass-specific enthalpy, respectively. $P_{\infty}, T_{\infty}, \rho_{\infty}, M_{\infty}$, $U_{\infty}$, and $R e_{\infty}^{\text {unit }}$ are the freestream pressure, temperature, density, Mach number, and unit Reynolds number, respectively

\begin{tabular}{|c|c|c|c|c|c|c|c|c|c|c|c|c|c|}
\hline \multirow[t]{2}{*}{ Set } & \multirow[t]{2}{*}{ Shot } & \multicolumn{3}{|c|}{ Test Gas } & \multirow{2}{*}{$\begin{array}{l}P_{R} \\
(\mathrm{MPa})\end{array}$} & \multirow{2}{*}{$\begin{array}{l}T_{R} \\
(\mathrm{~K})\end{array}$} & \multirow{2}{*}{$\begin{array}{l}h_{R} \\
(\mathrm{MJ} / \mathrm{kg})\end{array}$} & \multirow{2}{*}{$\begin{array}{l}P_{\infty} \\
(\mathrm{kPa})\end{array}$} & \multirow{2}{*}{$\begin{array}{l}T_{\infty} \\
(\mathrm{K})\end{array}$} & \multirow{2}{*}{$\begin{array}{l}\rho_{\infty} \\
\left(\mathrm{kg} / \mathrm{m}^{3}\right)\end{array}$} & \multirow[t]{2}{*}{$M_{\infty}$} & \multirow{2}{*}{$\begin{array}{l}U_{\infty} \\
(\mathrm{m} / \mathrm{s})\end{array}$} & \multirow{2}{*}{$\begin{array}{l}R e_{\infty}^{\text {unit }} \\
(1 / \mathrm{m})\end{array}$} \\
\hline & & $\% \mathrm{Kr}$ & $\% \mathrm{~N}_{2}$ & $\% \mathrm{O}_{2}$ & & & & & & & & & \\
\hline \multirow[t]{4}{*}{1} & 2909 & 3 & 97 & 0 & 19.9 & 4483 & 4.94 & 4.07 & 444 & 0.032 & 7.16 & 2983 & $4.61 \times 10^{6}$ \\
\hline & 2910 & 1 & 99 & 0 & 20.4 & 4489 & 5.18 & 4.44 & 461 & 0.033 & 7.02 & 3039 & $4.03 \times 10^{6}$ \\
\hline & 2926 & 1 & 99 & 0 & 14.8 & 3948 & 4.57 & 3.97 & 421 & 0.0 & 6.80 & 2850 & $3.81 \times 10^{6}$ \\
\hline & 2927 & 5 & 75 & 20 & 18.1 & 3700 & 4.65 & 5.63 & 552 & 0.035 & 6.09 & 2836 & $3.56 \times 10^{6}$ \\
\hline \multirow[t]{2}{*}{2} & 2928 & 1 & 99 & 0 & 16.6 & 6097 & 7.87 & 3.97 & 723 & 0.019 & 6.71 & 3675 & $2.00 \times 10^{6}$ \\
\hline & 2929 & 5 & 75 & 20 & 17.3 & 5024 & 7.55 & 6.50 & 1037 & 0.021 & 5.50 & 3502 & $1.81 \times 10^{6}$ \\
\hline \multirow[t]{2}{*}{3} & 2930 & 1 & 99 & 0 & 20.7 & 8335 & 15.7 & 7.24 & 1665 & 0.014 & 5.80 & 4894 & $1.25 \times 10^{6}$ \\
\hline & 2931 & 1 & 99 & 0 & 21.0 & 8376 & 15.9 & 7.45 & 1695 & 0.014 & 5.14 & 4940 & $1.26 \times 10^{6}$ \\
\hline 4 & 2933 & 1 & 99 & 0 & 22.4 & 5379 & 6.60 & 5.52 & 611 & 0.030 & 6.75 & 3400 & $3.39 \times 10^{6}$ \\
\hline
\end{tabular}

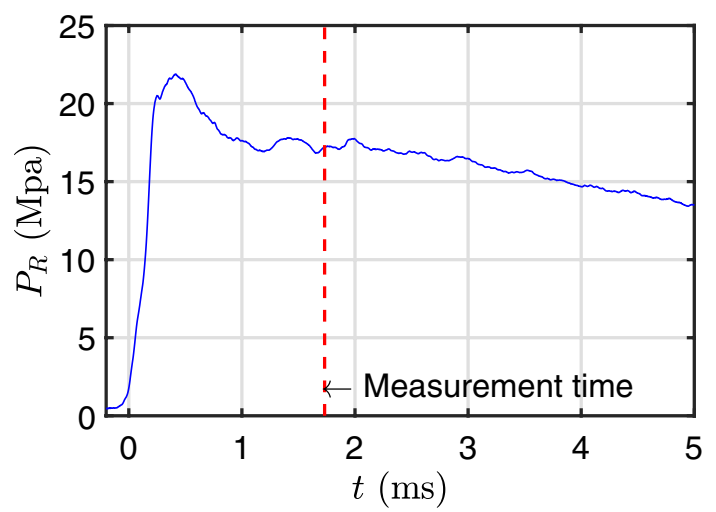

Fig. 3 Representative pressure reservoir trace. The trace is shown for Shot 2929

(3) Fourier filtering is performed by transforming into wavenumber space and applying a low-pass filter that removed structures with wavenumbers above $8001 / \mathrm{m}$ in the spanwise-direction (Rzeszotarski et al. 1983; Shapiro and Stockman 2001). Without the Fourier filtering in the spanwise direction, obtaining consistent results for the higher-enthalpy cases would not have been possible.

(4) The Gaussian peak finding algorithm from O'Haver (1997) was applied to find the line centers for the top row using the lines in the top row of each image as a first guess.

(5) Proceeding from the top-down, the Gaussian peak finding algorithm from O'Haver (1997) was applied to find the line centers for each row using the line center location immediately above as the guess.
Error bars for the KTV measurements are calculated in the same fashion as Zahradka et al. (2016) as

$$
\begin{aligned}
\widetilde{U}_{\mathrm{KTV}}= & {\left[\left(\widetilde{\Delta x} \frac{\partial U}{\partial \Delta x}\right)^{2}+\left(\widetilde{\Delta t} \frac{\partial U}{\partial \Delta t}\right)^{2}+\right.} \\
& \left.+\left(v_{R M S}^{\prime} \frac{\partial U}{\partial y} \Delta t\right)^{2}\right]^{\frac{1}{2}},
\end{aligned}
$$

where uncertainty estimates of a variable are indicated with a tilde and $U=\Delta x / \Delta t$. The uncertainty in the measured displacement distance, $\widetilde{\Delta x}$, of the excited $\mathrm{Kr}$ tracer is estimated as the $95 \%$ confidence bound on the write and read locations from the Gaussian fits, $\approx 10$ microns. The uncertainty in time, $\widetilde{\Delta t}$, is estimated to be half the camera gate width, $50 \mathrm{~ns}$, causing fluorescence blurring (Bathel et al. 2011). The third term in Eq. 1 is uncertainty in streamwise velocity due to wall-normal fluctuations in the $x y$-plane (Hill and Klewicki 1996; Bathel et al. 2011), where $v_{R M S}^{\prime}$ is estimated as the mean of the wall-normal velocity at the nozzle exit, approximately $40 \mathrm{~m} / \mathrm{s}$. We note the third term in Eq. 1 is relatively small in these experiments because there is little slope in the measured profiles.

The results for shots 2909, 2910, 2926-2931, and 2933 are shown in Figs. 4, 5, 6, 7. For each experiment, the plot on the left is the concatenation of normalized write and read KTV images. Peaks of Gaussian fits (in red) are plotted on these images. The plot on the right shows the derived KTV velocity profile in blue, the uncertainty estimate as black bars, and the computational results in red. The field of view of the KTV measurements is $20-35 \times 3.5 \mathrm{~mm}$ and the uncertainty is typically $5 \%$ of the freestream value. The zero in Figs. 4, 5, 6, 7 marks the centerline of the nozzle, and we note the measurement was made immediately downstream of the exit plane of the nozzle. 

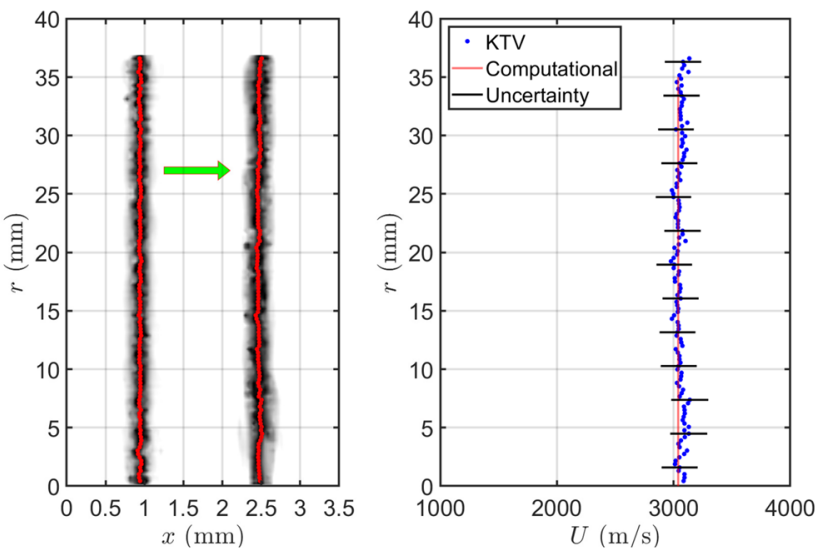

(a) Shot 2909
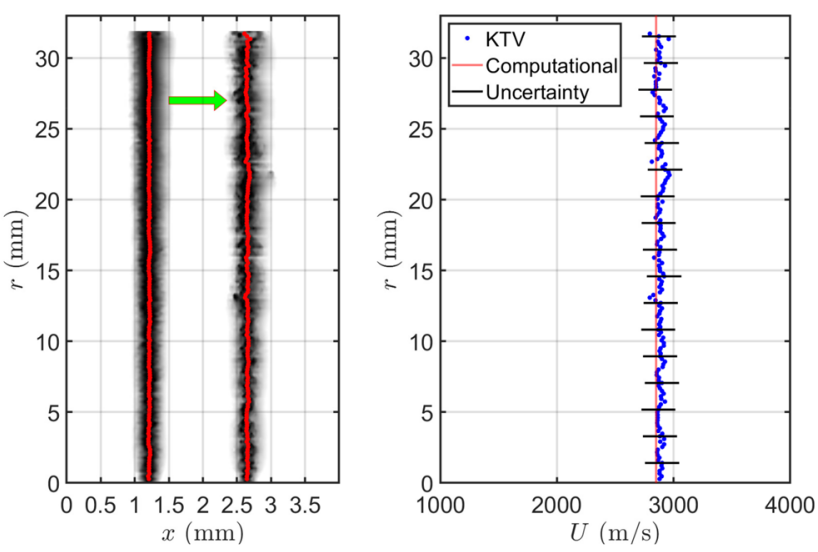

(c) Shot 2926

Fig. 4 Shots with reservoir enthalpy of approximately $4.5-5 \mathrm{MJ} / \mathrm{kg}$ and freestream pressure of $4.07-5.63 \mathrm{kPa}$. In each subfigure, left is the concatenation of processed write and read KTV images (inverted Scale); and right is the KTV-obtained velocity profile in blue, error
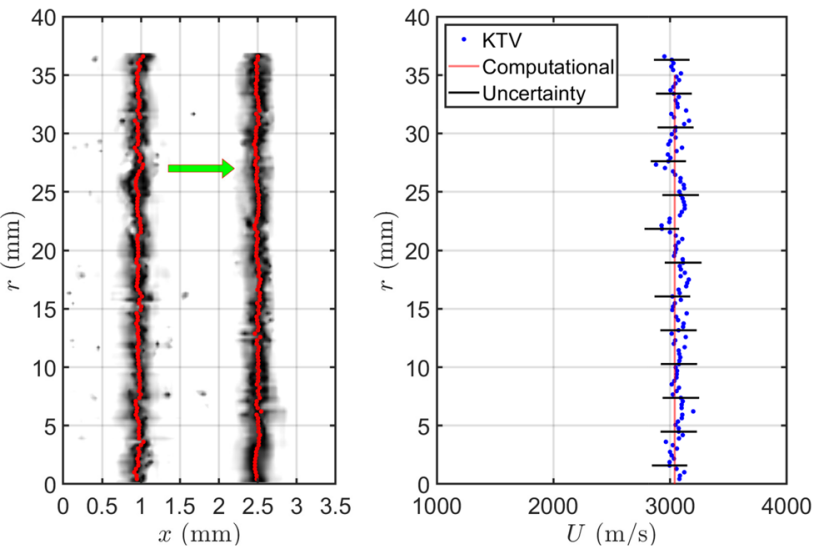

(b) Shot 2910
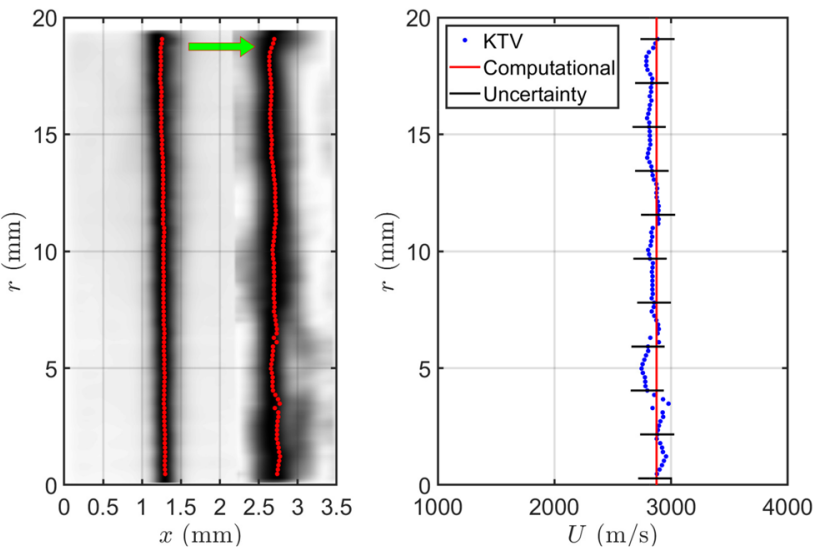

(d) Shot 2927

bars in black, and computational results in red. The time of displacement is $\Delta t=500 \mathrm{~ns}$. Gas mixtures were $97 \% \mathrm{~N}_{2} / 3 \% \mathrm{Kr}(\mathbf{a}), 99 \% \mathrm{~N}_{2}$ $/ 1 \% \mathrm{Kr}(\mathbf{b}$ and $\mathbf{c})$, and $75 \% \mathrm{~N}_{2} / 20 \% \mathrm{O}_{2} / 5 \% \mathrm{Kr}$ (d)
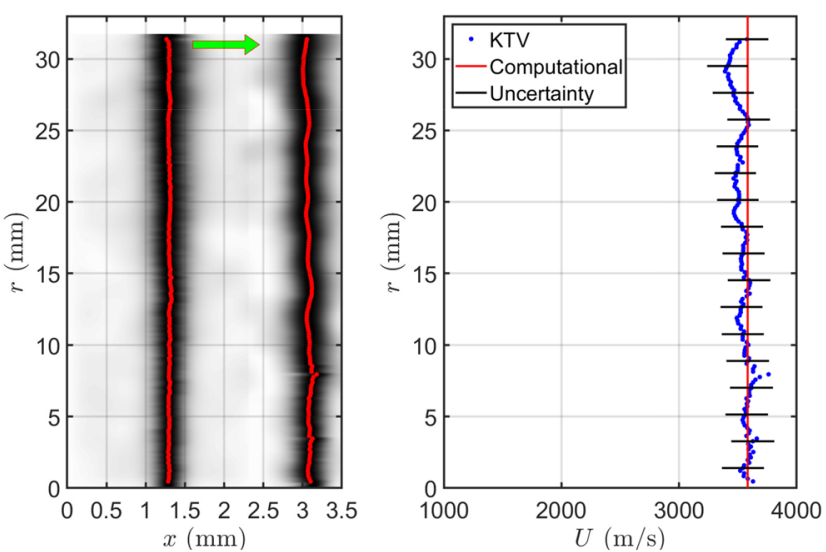

(a) Shot 2928
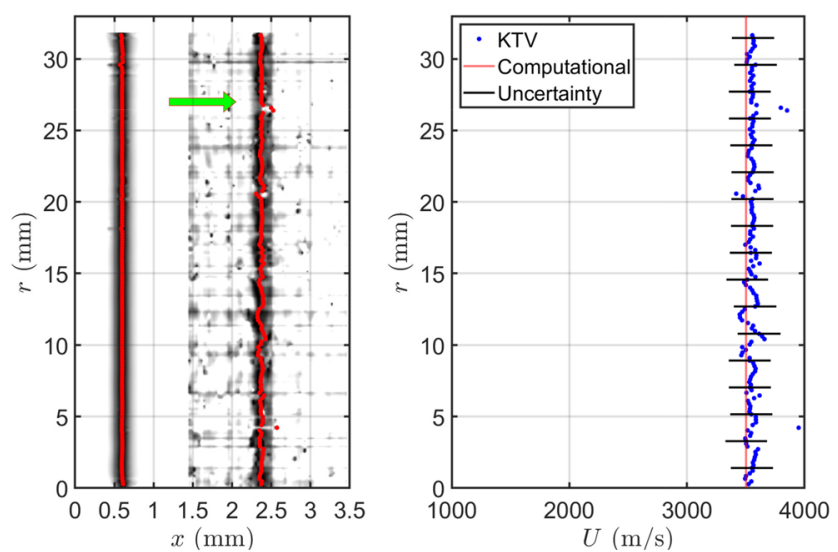

(b) Shot 2929

Fig. 5 Shots with reservoir enthalpy of approximately $7-8 \mathrm{MJ} / \mathrm{kg}$ and freestream pressure of $\approx 6.5 \mathrm{kPa}$. Same layout as Fig. 4 . Gas mixtures were $99 \% \mathrm{~N}_{2} / 1 \% \mathrm{Kr}(\mathbf{a})$, and $75 \% \mathrm{~N}_{2} / 20 \% \mathrm{O}_{2} / 5 \% \mathrm{Kr}(\mathbf{b})$ 

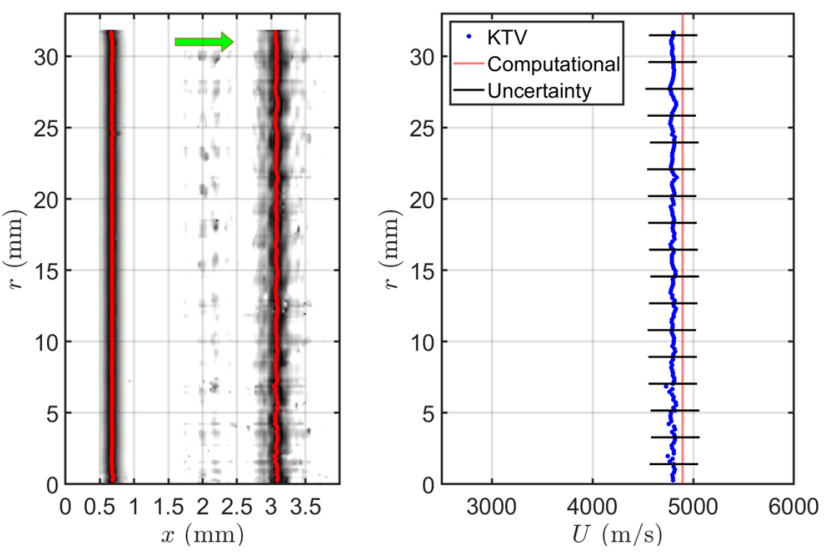

(a) Shot 2930
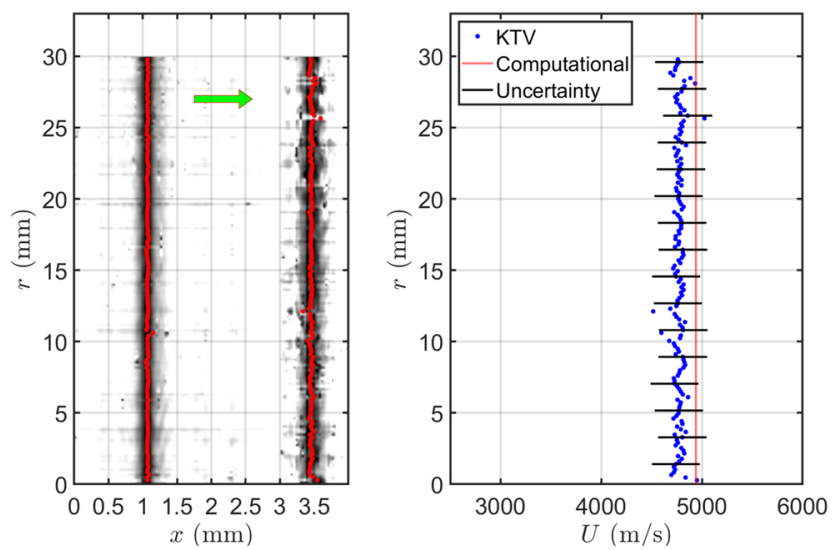

(b) Shot 2931

Fig. 6 Shots with reservoir enthalpy of 16.7-16.9 MJ/kg and freestream pressure of 9.44-9.59 kPa. Same layout as Fig. 4. Gas mixtures are 99\% $\mathrm{N}_{2} / 1 \% \mathrm{Kr}(\mathbf{a}$ and $\mathbf{b})$
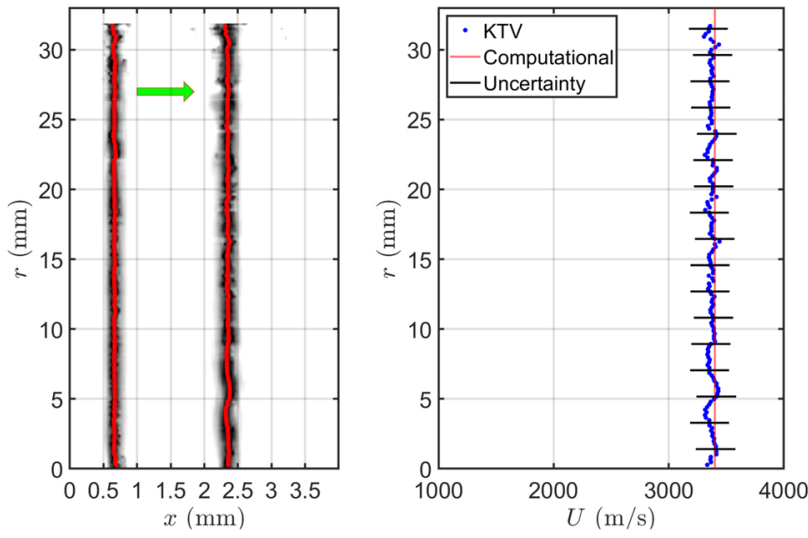

Fig. 7 Shot 2933 with reservoir enthalpy of $6.7 \mathrm{MJ} / \mathrm{kg}$ and freestream pressure of $8.07 \mathrm{kPa}$. Same layout as Fig. 4. Gas mixture was $99 \% \mathrm{~N}_{2}$ $/ 1 \% \mathrm{Kr}$

\section{Discussion}

The experimental conditions in Mustafa et al. (2019b) showed that KTV could be performed at static conditions similar to the T5 freestream with $99 \% \mathrm{~N}_{2} / 1 \% \mathrm{Kr}$, and $75 \%$ $\mathrm{N}_{2} / 20 \% \mathrm{O}_{2} / 5 \% \mathrm{Kr}$ gas mixtures. Relative to Mustafa et al. (2019b), the experiments described in the present work are significantly more complex due to (a) the longer standoff distance from the KTV LIF to the camera; (b) lower write-laser power, $10 \mathrm{~mJ} /$ pulse in Mustafa et al. (2019b) versus 3-4 mJ/pulse in this work; (c) timing complexity; (d) laser-power attenuation resulting from not triggering the laser setup at the designed repetition rate of $10 \mathrm{~Hz}$; (e) freestream luminosity; and, (f) scheduling complications of single-shot-per-day experiments.

\subsection{Choice of gas mixtures and quenching effects}

In light of the complexity associated with performing experiments in T5, the first experiment was performed with the $97 \% \mathrm{~N}_{2} / 3 \% \mathrm{Kr}$ mixture to serve as a conservative baseline of what could be done with KTV in a large-scale, highenthalpy reflected-shock tunnel. This successful experiment led us to use the $99 \% \mathrm{~N}_{2} / 1 \% \mathrm{Kr}$ and $75 \% \mathrm{~N}_{2} / 20 \% \mathrm{O}_{2} / 5 \%$ $\mathrm{Kr}$ gas mixtures in subsequent experiments. We dope the air mixture with $5 \% \mathrm{Kr}$, as opposed to the $1 \%$ used in the $\mathrm{N}_{2}$ experiments, because of the additional quenching from $\mathrm{O}_{2}$. We found these levels of $\mathrm{Kr}$ doping to be sufficient in previous experiments (Mustafa et al. 2019b). Referring to the energy level diagram in Fig. 1, the increased quenching effects occur in at least two ways: (1) fluorescence quenching of transitions $\mathrm{C}, \mathrm{D}$, and $\mathrm{F}$ through $\mathrm{L}$, and (2) collisional quenching of the metastable state via $5 s[3 / 2]_{2}^{0} \rightarrow 4 p^{6}$. Fluorescence quenching (1) reduces the fluorescence, thus reducing the SNR. Meanwhile, quenching of the metastable state (2) reduces the population of the $5 s[3 / 2]_{2}^{\circ}$ level, which in turn reduces the number $\mathrm{Kr}$ atoms to be re-excited with the $\mathrm{CW}$ laser diode (transition $\mathrm{E}$ in Fig. 1), thus reducing the SNR by reducing the number of $G$ and $F$ transitions to be imaged with the camera.

Experiments 2910 and 2926 were conducted approximately one year apart due to the COVID-19 pandemic (Fig. 4). All authors were present for shots 2909 and 2910, but the rest of the experiments were performed by the Caltech authors with virtual support by the Stevens authors. Shot 2926 served as a check on the experimental setup and assessed whether indeed this experiment could be performed quasi-remotely. The results from Shots 2910 and 2926 are nominally identical, giving some confidence in the repeatability of the measurement and robustness of the technique 
for other large-scale high-enthalpy facilities. One discrepancy in the results from these two shots is the location of the write-line focus, manifesting itself as a wider write line at $30 \mathrm{~mm}$ from the nozzle center line in shot 2926 than at the same location in shot 2910. In shot 2926, the focus appears to be at the nozzle center-line (approximately $0 \mathrm{~mm}$ ), and this was corrected to be located at approximately $10 \mathrm{~mm}$ in the experiments that followed; we note the write lines appear more uniform as a result.

At two nominal reservoir enthalpies, $\approx 5 \mathrm{MJ} / \mathrm{kg}$ and $\approx$ $8 \mathrm{MJ} / \mathrm{kg}$, we were able to perform experiments with the $99 \%$ $\mathrm{N}_{2} / 1 \% \mathrm{Kr}$ mixture and repeat it with the $75 \% \mathrm{~N}_{2} / 20 \% \mathrm{O}_{2} / 5 \%$ $\mathrm{Kr}$ mixture. This opens the possibility of performing experiments at these conditions with KTV to investigate nonequilibrium effects by fixing the run condition and executing an experiment with a more reactive or less reactive gas mixture.

\subsection{Effects of flow luminosity}

We observe some nonuniformity in the write line for shot 2910 (Fig. 4a), which is unusual for KTV or any tagging experiments; that is, the line should be straight because the flow has not yet had a chance to advect the tagged atoms or molecules. We speculate that this is due to sensor noise exacerbated by high levels of flow luminosity. The flow luminosity in $\mathrm{T} 5$ is nonuniform within each experiment in time and space, and is not repeatable from shot to shot at matching conditions. The luminosity could be a function of the tunnel operation during the previous experiment; that is, there could have been material that ablated and was deposited on the shock-tube wall following the run, and then on the following shot, this contaminant would be reintroduced to the test gas and present itself as nonuniform flow luminosity at the instant the write or read image is taken. Parziale et al. (2014) noted increased levels of noise during a shot that followed an experiment where a large amount of debris was introduced to the facility via ill-advised tunnel operation. During this campaign, there were no ill-advised experiments where a major amount of contamination would have been introduced to the flow on the following run; however, we note that there is still some run-to-run variation in flow luminosity likely due to these effects. Finally, we note that shock-tube cleanliness in T5 was the main focus of Jewell et al. (2017), where boundary-layer transition was noted to be inconsistent if proper shock-tube cleaning procedures were not followed. (They were followed in this work.)

To assess whether flow luminosity would be an issue at high-enthalpy conditions, two experiments were performed at $\approx 16 \mathrm{MJ} / \mathrm{kg}$. The first experiment in $99 \% \mathrm{~N}_{2} / 1 \% \mathrm{Kr}$ was successful, but the SNR was low relative to the other $99 \%$ $\mathrm{N}_{2} / 1 \%$ experiments at lower-enthalpy conditions. Therefore, we chose to repeat the experiment with the $99 \% \mathrm{~N}_{2} / 1 \% \mathrm{Kr}$ mixture. Noting the write pulse was only $4 \mathrm{~mJ} /$ pulse, it is likely that higher write-laser power would increase the SNR to sufficient levels to make measurements in the $75 \% \mathrm{~N}_{2}$ $120 \% \mathrm{O}_{2} / 5 \% \mathrm{Kr}$ mixture at the higher-enthalpy conditions.

\subsection{DPLR/KTV comparison and effects of uncertainty in calculation of run conditions on velocity}

The computations from the University of Minnesota Nozzle Code were in excellent agreement with the KTV-measured velocities, being between 0.43 and $3.3 \%$ in each of the nine experiments. Comparisons are presented in Table 3 . We note the broad range of enthalpy $(\approx 5-16 \mathrm{MJ} / \mathrm{kg}$ ) spanning nearly the entire usable envelope of T5 which is a test of the nonequilibrium thermochemical modeling incorporated into the Data Parallel Line Relaxation (DPLR) computational fluid dynamics code. That is, if a large modeling error or omission in DPLR was present, a significant error in the calculated velocity would be expected. In the two high-enthalpy cases $(\approx 16 \mathrm{MJ} / \mathrm{kg}), \mathrm{KTV}$ measurements of velocity were lower than the DPLR computations. The authors speculate that this could be the result of radiation losses in the reservoir, as $T_{R}>8000 \mathrm{~K}$. Quantifying the radiation losses in a reflected-shock tunnel is difficult, as was done in Logan et al. (1977). However, following Wittliff et al. (1959) to a first approximation, if we assume a 5\% reduction in reservoir enthalpy, $h_{R}$, due to radiation losses, this could explain the $2-3 \%$ velocity deficit at the higher enthalpy conditions. This could be an avenue for interesting further work.

As detailed in Sect. 3.1, the reservoir conditions are calculated using the initial driven section pressure, $P_{1}$, the measured incident shock speed $U_{s}$, and the measured reservoir pressure, $P_{R}$. The reservoir conditions, calculated from these measured parameters, are then input into the UM Nozzle code, giving the freestream conditions. To assess the bounds of error on the inputs to the nozzle code, we estimate the error in $P_{1}, U_{s}$, and $P_{R}$ as $1.5,1.5$ and $8 \%$ per Parziale (2013) and Jewell (2014). In Table 4, we observe

Table 3 Comparison of DPLR/KTV velocimetry results

\begin{tabular}{lllll}
\hline Shot & DPLR & \multicolumn{2}{l}{ KTV } & $\%$ \\
\cline { 3 - 4 } & $\mathrm{U}_{\infty}(\mathrm{m} / \mathrm{s})$ & $\bar{U}(\mathrm{~m} / \mathrm{s})$ & $\sigma(\mathrm{m} / \mathrm{s})$ & Difference \\
\hline 2909 & 2983 & 3056 & 33.0 & 0.572 \\
2910 & 3039 & 3059 & 52.3 & 0.657 \\
2926 & 2850 & 2884 & 27.6 & 1.18 \\
2927 & 2836 & 2848 & 44.6 & 0.425 \\
2928 & 3675 & 3567 & 56.0 & 2.94 \\
2929 & 3502 & 3553 & 55.8 & 1.47 \\
2930 & 4894 & 4797 & 15.5 & 1.99 \\
2931 & 4940 & 4775 & 51.3 & 3.33 \\
2933 & 3400 & 3372 & 26.6 & 0.818 \\
\hline
\end{tabular}


Table 4 Run-condition effect on calculated velocity from DPLR

\begin{tabular}{llll}
\hline Shot & $\widetilde{\Delta U_{\infty P_{1}}}(\%)$ & $\widetilde{\Delta U_{\infty P_{R}}}(\%)$ & $\widetilde{\Delta U_{\infty U_{s}}}(\%)$ \\
\hline 2929 & 0.05 & 0.76 & 0.98 \\
2931 & 0.10 & 0.67 & 0.85 \\
\hline
\end{tabular}

only small uncertainties in the freestream velocity due to these measured input uncertainties; for example, the change in freestream velocity due to the uncertainty in the shock speed being is $\widehat{\Delta U_{\infty U_{s}}} \approx 1 \%$.

\section{Conclusions}

KTV was performed successfully in the T5 Reflected-Shock Tunnel at Caltech. At reservoir enthalpies of $5 \mathrm{MJ} / \mathrm{kg}$ and $8 \mathrm{MJ} / \mathrm{kg}$, experiments were performed in $99 \% \mathrm{~N}_{2} / 1 \% \mathrm{Kr}$ and $75 \% \mathrm{~N}_{2} / 20 \% \mathrm{O}_{2} / 5 \% \mathrm{Kr}$ gas mixtures, thus allowing the possibility of performing experiments that investigate nonequilibrium effects. A $16 \mathrm{MJ} / \mathrm{kg}$ KTV experiment was performed twice in a $99 \% \mathrm{~N}_{2} / 1 \% \mathrm{Kr}$ gas mixture; with higher laser power, this experiment could likely be repeated in the air/ $\mathrm{Kr}$ mixture. The experiments at $\approx 16 \mathrm{MJ} / \mathrm{kg}$ had a freestream velocity of $\approx 4.94 \mathrm{~km} / \mathrm{s}$ which represent some of the highest experimentally-obtained velocities in the literature.

KTV-measured velocity profiles agree well with computationally obtained velocity profiles, to within the experimental error of the KTV technique. This agreement of experiment and computation in $\mathrm{N}_{2}$ and air flows over the range of $\approx 5-16 \mathrm{MJ} / \mathrm{kg}$ brings confidence to the $\mathrm{T} 5$ test condition calculation method, which inputs three experimentally measured quantities: (1) driven section initial pressure, (2) the incident shock speed, and (3) the reservoir pressure. If there were large systemic errors in this method or omissions in the underlying models in Cantera or the UM Nozzle code, one would expect a larger discrepancy in the freestream velocity or a trend in uncertainty for air vs. $\mathrm{N}_{2}$ flows due to the great complexity of calculating these reacting flows.

We note this experimental campaign was interrupted by the COVID-19 pandemic. Shots 2909 and 2910 were conducted in December 2019 with all authors present. Shots 2926-2933 were conducted in December 2020 by the Caltech group with remote help from the Stevens group, due to travel restrictions. This illustrates the utility, ease, and reliability of the KTV schemes with a pulsed-write laser and CW read laser in performing high-enthalpy research.

Acknowledgements We would like to acknowledge Prof. Hans Hornung of Caltech for providing valuable advice regarding all aspects of the project. Additionally, we would like to thank Bahram Valiferdowsi, also of Caltech, for operating the tunnel and assisting with the experimental setup.

\section{Declarations}

Conflict of interest The authors declare that they have no conflict of interest.

Funding Mustafa and Parziale were supported by AFOSR Young Investigator Program Grant FA9550-16-1-0262 and AFOSR Grant FA9550-18-1-0403; equipment for this work was supported by AFOSR DURIP Grants FA9550-15-1-0325 and FA9550-19-1-0182. Support was provided by US Air Force Small Business Innovation Research grants FA9101-17-P-0094 and FA2487-19-C-0013. Shekhtman was supported by the Stevens Institute of Technology Provost Fellowship and the ONR Young Investigator Research Program Grant N0001420-1-2549. Yu and Austin were partially supported by AFOSR Grant FA9550-19-1-0219.

\section{References}

André MA, Bardet PM, Burns RA, Danehy PM (2017) Characterization of hydroxyl tagging velocimetry for low-speed flows. Meas Sci Technol 28(8):085202. https://doi.org/10.1088/1361-6501/ aa7ac8

André MA, Burns RA, Danehy PM, Cadell SR, Woods BG, Bardet PM (2018) Development of $\mathrm{N}_{2} \mathrm{O}-\mathrm{MTV}$ for low-speed flow and in-situ deployment to an integral effect test facility. Exp Fluids 59(1):14. https://doi.org/10.1007/s00348-017-2470-3

Balla RJ (2013) Iodine tagging velocimetry in a mach 10 wake. AIAA J 51(7):1-3. https://doi.org/10.2514/1.J052416

Balla RJ, Everhart JL (2012) Rayleigh Scattering density measurements, Cluster theory, and nucleation calculations at mach 10 . AIAA J 50(3):698-707. https://doi.org/10.2514/1.J051334

Barker P, Bishop A, Rubinsztein-Dunlop H (1997) Supersonic velocimetry in a shock tube using laser enhanced ionisation and planar laser induced fluorescence. Appl Phys B 64(3):369-376. https:// doi.org/10.1007/s003400050186

Bathel BF, Danehy PM, Inman JA, Jones SB, Ivey CB, Goyne CP (2011) Velocity Profile measurements in hypersonic flows using sequentially imaged fluorescence-based molecular tagging. AIAA J 49(9):1883-1896. https://doi.org/10.2514/1.J050722

Boedeker LR (1989) Velocity measurement by $\mathrm{H}_{2} \mathrm{O}$ photolysis and laser-induced fluorescence of OH. Opt Lett 14(10):473-475. https://doi.org/10.1364/OL.14.000473

Brooks JM, Gupta AK, Smith MS, Marineau EC (2018) Particle image velocimetry measurements of Mach 3 turbulent boundary layers at low Reynolds numbers. Exp Fluids 59:83. https://doi.org/10. 1007/s00348-018-2536-X

Browne S, Ziegler J, Shepherd JE (2006) Numerical solution methods for shock and detonation jump Conditions. GALCIT - FM2006-006

Candler GV (2005) Hypersonic nozzle analysis using an excluded volume equation of state. In: Proceedings of 38th AIAA Thermophysics Conference, AIAA-2005-5202, Toronto, Ontario Canada, https://doi.org/10.2514/6.2005-5202

Candler GV (2015) Rate-dependent energetic processes in hypersonic flows. Prog Aerosp Sci 72:37-48. https://doi.org/10.1016/j.paero sci.2014.09.006

Candler GV (2019) Rate effects in hypersonic flows. Ann Rev Fluid Mech 51:379-402. https://doi.org/10.1146/annur ev-fluid-010518-040258

Dakka MA, Tsiminis G, Glover RD, Perrella C, Moffatt J, Spooner NA, Sang RT, Light PS, Luiten AN (2018) Laser-based metastable krypton generation. Phys Rev Lett 121:093201. https://doi.org/ 10.1103/PhysRevLett.121.093201 
Dam N, Klein-Douwel RJH, Sijtsema NM, ter Meulen JJ (2001) Nitric oxide flow tagging in unseeded air. Opt Lett 26(1):36-38. https:// doi.org/10.1364/OL.26.000036

Danehy PM, O'Byrne S, Houwing AFP, Fox JS, Smith DR (2003) Flow-tagging velocimetry for hypersonic flows using fluorescence of nitric oxide. AIAA J 41(2):263-271. https://doi.org/10.2514/2. 1939

Danehy PM, Weisberger J, Johansen C, Reese D, Fahringer T, Parziale NJ, Dedic C, Estevadeordal J, Cruden BA (2018) Non-intrusive measurement techniques for flow characterization of hypersonic wind tunnels. In: flow characterization and modeling of hypersonic wind tunnels (NATO Science and Technology Organization Lecture Series STO-AVT 325), NF1676L-31725 - Von Karman Institute, Brussels, Belgium

Eckbreth AC (1996) Laser diagnostics for combustion temperature and species, 2nd edn. Gordon and Breach Publications, London, pp 381-452

Edwards MR, Dogariu A, Miles RB (2015) Simultaneous temperature and velocity measurements in air with femtosecond laser tagging. AIAA J 53(8):2280-2288. https://doi.org/10.2514/1.J053685

Gendrich CP, Koochesfahani MM (1996) A spatial correlation technique for estimating velocity fields using molecular tagging velocimetry (MTV). Exp Fluids 22(1):67-77. https://doi.org/10. 1007/BF01893307

Gendrich CP, Koochesfahani MM, Nocera DG (1997) Molecular tagging velocimetry and other novel applications of a new phosphorescent supramolecule. Exp Fluids 23(5):361-372. https://doi.org/ $10.1007 / \mathrm{s} 003480050123$

Goodwin DG (2003) An Open-source, extensible software suite for CVD process simulation. In: Proceedings of CVD XVI and EuroCVD Fourteen, M Allendorf, F Maury, and F Teyssandier (Eds.), pp 155-162

Goodwin DG (2003) An Open-source, extensible software suite for CVD process simulation. In: Proceedings of CVD XVI and EuroCVD Fourteen, M Allendorf, F Maury, and F Teyssandier (Eds.), pp 155-162

Haertig J, Havermann M, Rey C, George A (2002) Particle image velocimetry in mach 3.5 and 4.5 shock-tunnel flows. AIAA J 40(6):1056-1060. https://doi.org/10.2514/2.1787

Handa T, Mii K, Sakurai T, Imamura K, Mizuta S, Ando Y (2014) Study on supersonic rectangular microjets using molecular tagging velocimetry. Exp Fluids 55(5):1-9. https://doi.org/10.1007/ s00348-014-1725-5

Havermann M, Haertig J, Rey C, George A (2008) PIV measurements in shock tunnels and shock tubes. Springer, Berlin Heidelberg, pp 429-443

Hill RB, Klewicki JC (1996) Data reduction methods for flow tagging velocity measurements. Exp Fluids 20(3):142-152. https://doi. org/10.1007/BF00190270

Hiller B, Booman RA, Hassa C, Hanson RK (1984) Velocity visualization in gas flows using laser-induced phosphorescence of biacetyl. Rev Sci Instr 55(12):1964-1967. https://doi.org/10.1063/1.11376 87

Hornung HG (1992) Performance data of the new free-piston shock tunnel at GALCIT. In: Proceedings of 17th AIAA Aerospace Ground Testing Conference, AIAA 1992-3943, Nashville, TN, https://doi.org/10.2514/6.1992-3943

Hornung HG (1993) Experimental hypervelocity flow simulation, needs, achievements and limitations. In: Proceedings of the First Pacific International Conference on Aerospace Science and Technology, Taiwan

Hsu AG, Srinivasan R, Bowersox RDW, North SW (2009a) Molecular tagging using vibrationally excited nitric oxide in an underexpanded jet flowfield. AIAA J 47(11):2597-2604. https://doi.org/ $10.2514 / 1.39998$
Hsu AG, Srinivasan R, Bowersox RDW, North SW (2009b) Two-component molecular tagging velocimetry utilizing NO fluorescence lifetime and $\mathrm{NO}_{2}$ photodissociation techniques in an underexpanded jet flowfield. Appl Opt 48(22):4414-4423. https://doi. org/10.1364/AO.48.004414

Jewell JS (2014) Boundary-layer transition on a slender cone in hypervelocity flow with real gas effects. $\mathrm{PhD}$ thesis, California Institute of Technology

Jewell JS, Parziale NJ, Leyva IA, Shepherd JE (2017) Effects of shocktube cleanliness on hypersonic boundary layer transition at high enthalpy. AIAA J 55(1):332-338. https://doi.org/10.2514/1.J0548 97

Jiang N, Halls BR, Stauffer HU, Danehy PM, Gord JR, Roy S (2016) Selective two-photon absorptive resonance femtosecond-laser electronic-excitation tagging velocimetry. Opt Lett 41(10):22252228. https://doi.org/10.1364/OL.41.002225

Jiang N, Mance JG, Slipchenko MN, Felver JJ, Stauffer HU, Yi T, Danehy PM, Roy S (2017) Seedless velocimetry at $100 \mathrm{khz}$ with picosecond-laser electronic-excitation tagging. Opt Lett 42(2):239-242. https://doi.org/10.1364/OL.42.000239

Johnson HB (2000) Thermochemical interactions in hypersonic boundary layer stabity. PhD thesis, University of Minnesota, Minneapolis , Minnesota

Kramida A, Yu Ralchenko, Reader J (2020) and NIST ASD Team NIST Atomic Spectra Database (ver. 5.5.6), [Online]. Available: https://physics.nist.gov/asd (2020) April 16]. National Institute of Standards and Technology, Gaithersburg, MD

Van der Laan WPN, Tolboom RAL, Dam NJ, ter Meulen JJ (2003) Molecular tagging velocimetry in the wake of an object in supersonic flow. Exp Fluids 34(4):531-534. https://doi.org/10.1007/ s00348-003-0593-1

Lempert WR, Jiang N, Sethuram S, Samimy M (2002) Molecular tagging velocimetry measurements in supersonic microjets. AIAA J 40(6):1065-1070. https://doi.org/10.2514/2.1789

Lempert WR, Boehm M, Jiang N, Gimelshein S, Levin D (2003) Comparison of molecular tagging velocimetry data and direct simulation monte carlo simulations in supersonic micro jet flows. Exp Fluids 34(3):403-411. https://doi.org/10.1007/s00348-002-0576-7

Leyva IA (2017) The relentless pursuit of hypersonic flight. Phys Today 70(11):30-36. https://doi.org/10.1063/PT.3.3762

Logan PF, Stalker RJ, McIntosh MK (1977) A shock tube study of radiative energy loss from an argon plasma. J Phys D Appl Phys 10(3):323-337. https://doi.org/10.1088/0022-3727/10/3/012

Loth E (2008) Compressibility and Rarefaction effects on drag of a spherical particle. AIAA J 46(9):2219-2228. https://doi.org/10. 2514/1.28943

Lowe KT, Byun G, Simpson RL (2014) The effect of particle lag on supersonic turbulent boundary layer statistics. In: Proceedings of AIAA SciTech 2014, AIAA-2014-0233, National Harbor, Maryland, https://doi.org/10.2514/6.2014-0233

Lu FK, Marren DE (2002) Advanced hypersonic test facilities. AIAA 10(2514/4):866678

McBride BJ, Zehe MJ, Gordon S (2002) NASA Glenn coefficients for calculating thermodynamic properties of individual species. NASA TP-2002-211556

McDaniel JC, Hiller B, Hanson RK (1983) Simultaneous multiplepoint velocity measurements using laser-induced iodine fluorescence. Opt Lett 8(1):51-53. https://doi.org/10.1364/OL.8.000051

McIntosh MK (1971) Free stream velocity measurements in a high enthalpy shock tunnel. Phys Fluids 14(6):1100-1102. https://doi. org/10.1063/1.1693570

Michael JB, Edwards MR, Dogariu A, Miles RB (2011) Femtosecond laser electronic excitation tagging for quantitative velocity imaging in air. Appl Opt 50(26):5158-5162. https://doi.org/10.1364/ AO. 50.005158 
Miles R, Cohen C, Connors J, Howard P, Huang S, Markovitz E, Russell G (1987) Velocity measurements by vibrational tagging and fluorescent probing of oxygen. Opt Lett 12(11):861-863. https:// doi.org/10.1364/OL.12.000861

Miles R, Connors J, Markovitz E, Howard P, Roth G (1989) Instantaneous profiles and turbulence statistics of supersonic free shear layers by Raman excitation plus laser-induced electronic fluorescence (RELIEF) velocity tagging of oxygen. Exp Fluids 8(1-2):17-24. https://doi.org/10.1007/BF00203060

Miles RB, Lempert WR (1997) Quantitative flow visualization in unseeded flows. Ann Rev Fluid Mech 29(1):285-326. https://doi. org/10.1146/annurev.fluid.29.1.285

Miles RB, Zhou D, Zhang B, Lempert WR (1993) Fundamental turbulence measurements by RELIEF flow tagging. AIAA J 31(3):447452. https://doi.org/10.2514/3.11350

Miles RB, Grinstead J, Kohl RH, Diskin G (2000) The RELIEF flow tagging technique and its application in engine testing facilities and for helium-air mixing studies. Meas Sci Technol 11(9):12721281. https://doi.org/10.1088/0957-0233/11/9/304

Miller JC (1989) Two-photon resonant multiphoton ionization and stimulated emission in krypton and xenon. Phys Rev A 40:69696976. https://doi.org/10.1103/PhysRevA.40.6969

Mills JL (2016) Investigation of multi-photon excitation in argon with applications in hypersonic flow diagnostics. PhD thesis, Old Dominion University

Mills JL, Sukenik CI, Balla RJ (2011) Hypersonic wake diagnostics using laser induced fluorescence techniques. In: Proceedings of 42nd AIAA Plasmadynamics and Lasers Conference, AIAA 20113459, Honolulu, Hawaii, https://doi.org/10.2514/6.2011-3459

Mustafa MA, Parziale NJ (2018) Simplified read schemes for krypton tagging velocimetry in $\mathrm{N}_{2}$ and air. Opt Lett 43(12):2909-2912. https://doi.org/10.1364/OL.43.002909

Mustafa MA, , Parziale NJ (2017a) Krypton tagging velocimetry in the stevens shock tube. In: Proceedings of 33rd AIAA Aerodynamic Measurement Technology and Ground Testing Conference, AIAA-2017-3897, Denver, Colorado, https://doi.org/10.2514/6. 2017-3897

Mustafa MA, Hunt MB, Parziale NJ, Smith MS, Marineau EC (2017b) Krypton tagging velocimetry (KTV) investigation of shock-wave/ turbulent boundary-layer interaction. In: Proceedings of AIAA SciTech 2017, AIAA-2017-0025, Grapevine, Texas, https://doi. org/10.2514/6.2017-0025

Mustafa MA, Parziale NJ, Smith MS, Marineau EC (2017c) Nonintrusive freestream velocity measurement in a large-scale hypersonic wind tunnel. AIAA J 55(10):3611-3616. https://doi.org/10. 2514/1.J056177

Mustafa MA, Parziale NJ, Smith MS, Marineau EC (2018) Two-dimensional krypton tagging velocimetry (KTV-2D) investigation of shock-wave/turbulent boundary-layer interaction. In: Proceedings of AIAA SciTech 2018, AIAA-2018-1771, Kissimmee, Florida, https://doi.org/10.2514/6.2018-1771

Mustafa MA, Parziale NJ, Smith MS, Marineau EC (2019a) Amplification and structure of streamwise-velocity fluctuations in compression-corner shock-wave/turbulent boundary-layer interactions. J Fluid Mech 863:1091-1122. https://doi.org/10.1017/jfm.2018. 1029

Mustafa MA, Shekhtman D, Parziale NJ (2019b) Single-laser krypton tagging velocimetry investigation of supersonic air and $\mathrm{N}_{2}$ boundary-layer flows over a hollow cylinder in a shock tube. Phys Rev Appl 11(6):064013. https://doi.org/10.1103/PhysRevApplied. 11.064013

O'Haver T (1997) A pragmatic introduction to signal processing. University of Maryland at College Park, College Park

Parker RA, Wakeman T, MacLean M, Holden M (2007) Measuring nitric oxide freestream velocity using a quantum cascade laser at CUBRC. In: Proceedings of 45th AIAA Aerospace Sciences
Meeting and Exhibit, AIAA-2007-1329, Kissimmee, Florida, https://doi.org/10.2514/6.2007-1329

Parziale NJ (2013) Slender-body hypervelocity boundary-layer instability. PhD thesis, California Institute of Technology

Parziale NJ, Shepherd JE, Hornung HG (2014) Free-stream density perturbations in a reflected-shock tunnel. Exp Fluids 55(2):1665. https://doi.org/10.1007/s00348-014-1665-0

Parziale NJ, Smith MS, Marineau EC (2015) Krypton tagging velocimetry of an underexpanded jet. Appl Opt 54(16):5094-5101. https://doi.org/10.1364/AO.54.005094

Pitz RW, Lahr MD, Douglas ZW, Wehrmeyer JA, Hu S, Carter CD, Hsu KY, Lum C, Koochesfahani MM (2005) Hydroxyl tagging velocimetry in a supersonic flow over a cavity. Appl Opt 44(31):6692-6700. https://doi.org/10.1364/AO.44.006692

Ribarov LA, Wehrmeyer JA, Batliwala F, Pitz RW, DeBarber PA (1999) Ozone tagging velocimetry using narrowband excimer lasers. AIAA J 37(6):708-714. https://doi.org/10.2514/2.799

Rzeszotarski MS, Royer FL, Gilmore GC (1983) Review and assessment of turbulence models for hypersonic flows. Behav Res Methods Imstr 15(2):308-318. https://doi.org/10.3758/BF032 03566

de Matos SPA, Barreta LG, Martins CA (2018) Velocity and NO-lifetime measurements in an unseeded hypersonic air flow. J Fluids Eng 140(12):121105

Sánchez-González R, Srinivasan R, Bowersox RDW, North SW (2011) Simultaneous velocity and temperature measurements in gaseous flow fields using the venom technique. Opt Lett 36(2):196-198. https://doi.org/10.1364/OL.36.000196

Sánchez-González R, Bowersox RDW, North SW (2012) Simultaneous velocity and temperature measurements in gaseous flowfields using the vibrationally excited nitric oxide monitoring technique: a comprehensive study. Appl Opt 51(9):1216-1228. https://doi. org/10.1364/AO.51.001216

Sánchez-González R, Bowersox RDW, North SW (2014) Vibrationally excited $\mathrm{NO}$ tagging by $\mathrm{NO}\left(\mathrm{A}^{2} \Sigma^{+}\right)$fluorescence and quenching for simultaneous velocimetry and thermometry in gaseous flows. Opt Lett 39(9):2771-2774. https://doi.org/10.1364/OL.39.002771

Schneider SP (2008) Development of hypersonic quiet tunnels. J Spacecr Rockets 45(4):641-664. https://doi.org/10.2514/1.34489

Shapiro LG, Stockman GC (2001) Computer vision. Pearson Eduction, London

Shekhtman D, Mustafa MA, Parziale NJ (2020) Two-photon crosssection calculations for krypton in the 190-220 nm range. Appl Opt 59(34):10826-10837. https://doi.org/10.1364/AO.410806

Shekhtman D, Mustafa MA, Parziale NJ (2021) Excitation line optimization for krypton tagging velocimetry and planar laser-induced fluorescence in the 200-220 nm range. In: Proceedings of AIAA SciTech 2021, AIAA-2021-1300, Virtual Event, https://doi.org/ 10.2514/6.2021-1300

Shiu Y, Biondi MA (1977) Dissociative recombination in krypton: dependence of the total rate coefficient and excited-state production on electron temperature. Phys Rev Appl 16:1817-1820. https://doi.org/10.1103/PhysRevA.16.1817

Sijtsema NM, Dam NJ, Klein-Douwel RJH, ter Meulen JJ (2002) Air photolysis and recombination tracking: a new molecular tagging velocimetry scheme. AIAA J 40(6):1061-1064. https://doi.org/ $10.2514 / 2.1788$

Stalker RJ (1989) Hypervelocity aerodynamics with chemical nonequilibrium. Ann Rev Fluid Mech 21:37-60. https://doi.org/10.1146/ annurev.fluid.21.1.37

Stier B, Koochesfahani MM (1999) Molecular tagging velocimetry (MTV) measurements in gas phase flows. Exp Fluids 26(4):297304. https://doi.org/10.1007/s003480050292

Sudani N, Hornung HG (1998) Gasdynamical detectors of driver gas contamination in a high-enthalpy shock tunnel. AIAA 36(3):313319. https://doi.org/10.2514/2.383 
Sudani N, Valiferdowsi B, Hornung HG (2000) Test time increase by delaying driver gas contamination for reflected shock tunnels. AIAA 38(9):1497-1503. https://doi.org/10.2514/2.1138

Tropea C, Yarin AL, Foss JF (2007) Springer handbook of experimental fluid mechanics. Springer, Berlin

Wagner JL, DeMauro EP, Casper KM, Beresh SJ, Lynch KP, Pruett BO (2018) Pulse-burst PIV of an impulsively started cylinder in a shock tube for Re $>105$. Exp Fluids 59(6):106. https://doi.org/ 10.1007/s00348-018-2558-4

Wagnild RM (2012) High enthalpy effects on two boundary layer disturbances in supersonic and hypersonic flow. $\mathrm{PhD}$ thesis, University of Minnesota, Minnesota

Wehrmeyer JA, Ribarov LA, Oguss DA, Pitz RW (1999) Flame flow tagging velocimetry with $193-\mathrm{nm} \mathrm{h}_{2} \mathrm{o}$ photodissociation. Appl Opt 38(33):6912-6917. https://doi.org/10.1364/AO.38.006912

Williams OJH, Nguyen T, Schreyer AM, Smits AJ (2015) Particle response analysis for particle image velocimetry in supersonic flows. Phys Fluids 27(7):076101. https://doi.org/10.1063/1.49228 65
Wittliff CE, Wilson MR, Hertzberg A (1959) The Tailored-interface hypersonic shock tunnel. J Aerosp Sci 26(4):219-228. https://doi. org/10.2514/8.8016

Wright MJ, Candler GV, Prampolini M (1996) Data-parallel lowerupper relaxation method for the Navier-Stokes equations. AIAA J 34(7):1371-1377. https://doi.org/10.2514/3.13242

Zahradka D, Parziale NJ, Smith MS, Marineau EC (2016) Krypton tagging velocimetry in a turbulent mach 2.7 boundary layer. Exp Fluids 57:62. https://doi.org/10.1007/s00348-016-2148-2

Zhang S, Yu X, Yan H, Huang H, Liu H (2017) Molecular tagging velocimetry of $\mathrm{NH}$ fluorescence in a high-enthalpy rarefied gas flow. Appl Phy B 123(4):122. https://doi.org/10.1007/ s00340-017-6703-1

Publisher's Note Springer Nature remains neutral with regard to jurisdictional claims in published maps and institutional affiliations.

\section{Authors and Affiliations}

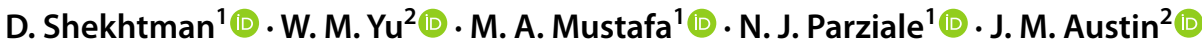

N. J. Parziale

nick.parizale@gmail.com

J. M. Austin

jmaustin@caltech.edu

1 Stevens Institute of Technology, Hoboken, NJ 07030, USA
2 California Institute of Technology, Pasadena, CA 91125, USA 